Research Paper

\title{
Upconverting Organic Dye Doped Core-Shell Nano-Composites for Dual-Modality NIR Imaging and Photo-Thermal Therapy
}

\author{
Guobin Shan, Ralph Weissleder, and Scott A. Hilderbrand ${ }^{凶}$ \\ Center for Systems Biology, Massachusetts General Hospital and Harvard Medical School, 185 Cambridge St, CPZN 5210, Boston, MA.
}

$\triangle$ Corresponding author: Center for Systems Biology, Massachusetts General Hospital and Harvard Medical School, 185 Cambridge St, CPZN 5210, Boston, MA 02114. Tel. 617-643-5679 Email Scott_Hilderbrand@hms.harvard.edu.

(c) Ivyspring International Publisher. This is an open-access article distributed under the terms of the Creative Commons License (http:/ / creativecommons.org/ licenses/by-nc-nd/3.0/). Reproduction is permitted for personal, noncommercial use, provided that the article is in whole, unmodified, and properly cited.

Received: 2012.09.15; Accepted: 2012.II.I4; Published: 2013.03.21

\begin{abstract}
Nanotechnology approaches offer the potential for creating new optical imaging agents with unique properties that enable uses such as combined molecular imaging and photo-thermal therapy. Ideal preparations should fluoresce in the near-infrared (NIR) region to ensure maximal tissue penetration depth along with minimal scattering and light absorption. Due to their unique photophysical properties, upconverting ceramics such as $\mathrm{NaYF}_{4}: \mathrm{Er}^{3+}, \mathrm{Yb}^{3+}$ nanoparticles have become promising optical materials for biological imaging. In this work, the design and synthesis of $\mathrm{NaYF}_{4}: \mathrm{Er}^{3+}, \mathrm{Yb}^{3+} @ \mathrm{SiO}_{2}$ core-shell nano-composites, which contain highly absorbing NIR carbocyanine dyes in their outer silica shell, are described. These materials combine optical emission (from the upconverting core nanoparticle) with strong NIR absorption (from the carbocyanine dyes incorporated into the shell) to enable both optical imaging and photo-thermal treatment, respectively. Ultimately, this hybrid composite nanomaterial approach imparts the ability to both visualize, via upconversion imaging, and treat, via photo-thermal heating, using two distinct optical channels. Proof-of-principle in vitro experiments are presented to demonstrate the combined imaging and photo-thermal properties of this new functional nano-composite.
\end{abstract}

Key words: Cell imaging, Core-shell, Dye, Nano-composites, Photo-thermal therapy, Up-conversion.

\section{Introduction}

Thermal therapies result in cell necrosis via lysis and rupture of cellular membranes and via the subsequent release of digestive enzymes. These therapies have thus recently come under investigation as a nonor minimally invasive alternative to conventional surgical treatment for cancer [1]. Photo-thermal therapy (PTT) is one type of thermal treatment in which the agents convert light energy into heat to induce cellular hyperthermia $[2,3]$. On account of their strong optical absorption properties, many nanomaterials including noble metal nanoparticles [4,5], carbon nanotubes $[6,7,8,9,10]$, quantum dots [11], and gra- phene oxide [12], have now been investigated as potential PTT materials[13].

The near-infrared (NIR) region $(650-1000 \mathrm{~nm})$ of the electromagnetic spectrum enables optimal light penetration due to low scattering and minimal absorption by biological tissues in this range [14]. NIR-absorbing gold nanostructures (nanoparticles (NPs) $[15,16]$, nanorods (NRs) $[17,18,19,20]$, nanoshells [21], nanocages [22], and hollow nanospheres [23]) recently have been the subject of intense investigation for PTT applications [24]. For example, gold NRs with suitable aspect ratios have been shown to absorb and 
scatter strongly in the NIR region $[25,26]$. The photo-thermal cell killing performance of these gold nanomaterials also has been investigated extensively [27], [28],[29]. In addition to gold-based composites, other hybrid nanomaterials such as gold nanocage carbon nanotube hybrids [30] and Ag@Au core-shell NPs [31], have been explored as possible PTT agents.

Organic NIR dyes that are fluorescent or capable of generating cytotoxic singlet oxygen $\left({ }^{1} \mathrm{O}_{2}\right)$, have been used for the visualization of deep tissues via fluorescence imaging [32], and for the noninvasive treatment of tumors by photodynamic therapy (PDT) $[33,34]$, respectively. The photo-thermal properties of NIR dyes have also been exploited for their potential application to hyperthermal treatment of cancer $[35,36]$. In terms of biomedical applications, organic NIR dyes have many advantageous features including a high light-absorptivity per mass, high fluorescence efficiency, and biocompatibility [37]. However, relatively little effort has been focused on investigating the potential use of these organic materials in PTT. This is in part because the application of small molecule organic dyes to PTT often suffers from problems such as low photo-thermal conversion efficiency due to competitive photophysical processes (e.g. fluorescence or intersystem crossing), and low photostability under intense and prolonged light irradiation. To address these issues, rather than use individual dye molecules, NIR-dye aggregates have been strategically employed as PTT agents. For this, polymers and silica have been shown to serve as excellent hosts for carrying aggregates. The inclusion of organic dyes into NPs not only improves the photostability of the dye but also quenches dye fluorescence[37,38]. In one recent report, aqueous suspensions of carbocyanine dye-loaded silica NPs were shown to increase the water temperature by $\sim 15^{\circ} \mathrm{C}$ following NIR excitation[38]. Furthermore, by using the same organic dye molecules as used for PTT in this silica composite, they were also shown to be well-suited to fluorescence imaging. However, dual use of these organic dyes requires the same excitation wavelength for both therapy and imaging, and will thus likely result in unintended photo-thermal heating during imaging experiments. One solution to this problem would be to incorporate two materials, that absorb in distinct optical channels, within a single NP. In this way, the first channel could be employed for imaging and diagnosis applications, leaving the second channel free for use in photo-thermal treatment. Unfortunately, an initial attempt at this approach, using aggregated NIR absorbing cyanine dyes and fluorescein cross-linked into separate layers of a core/shell silica NP, resulted in near complete quenching of the fluorescein fluorescence emission. Thus, as an alternative, we became interested in investigating the possibility of combining NIR-dye aggregates with upconverting NPs (UNPs). These upconverting materials, due to their anti-Stokes luminescent properties and NIR excitation at $980 \mathrm{~nm}$ [39], are an excellent candidate for use in concert with highly absorbing organic dyes for dual-function photo-thermal/optical imaging nanomaterials. In this work, we present a new nano-composite formulation that consists of a $\mathrm{NaYF}_{4}: \mathrm{Er}^{3+}, \mathrm{Yb}^{3+}$ nanoparticle (UNP) core that is surrounded by a silica shell doped with a high concentration of strongly absorbing NIR carbocyanine dye molecules. As shown in Scheme 1 (Figure A), the structure of the UNP@SiO$/$ /Dye nano-composite serves not only as an imaging agent but also as a NIR PTT agent.

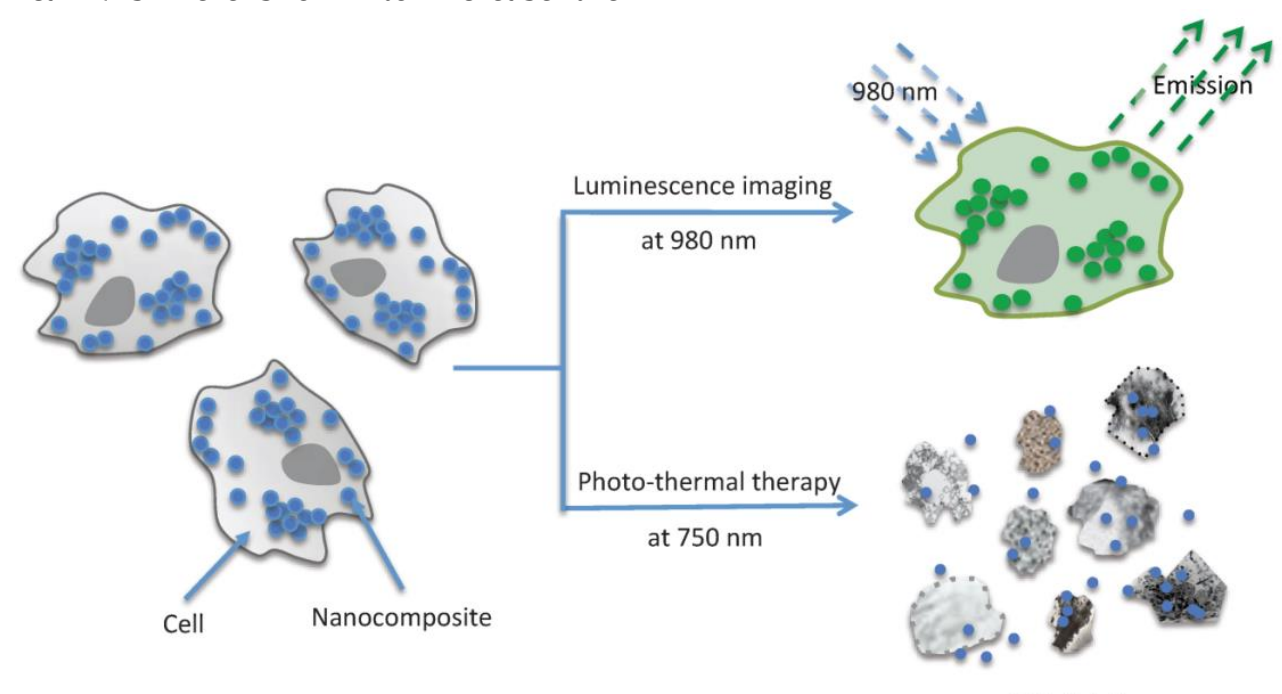

Cell debris

Figure A. (Scheme I) Application of UNP@SiO 2 /Dye nano-composites (Blue dots and Green dots) for optical imaging and photo-thermal therapy (cell disruption). 


\section{Experimental Section}

\section{Chemicals}

All chemicals were purchased from Sigma Aldrich (except where noted) and were used as received. (3-Mercaptopropyl)-triethoxy-silane (MPTES) was purchased from Fisher Scientific.

\section{Synthesis of $40 \mathrm{~nm} \mathrm{NaYF} 4: \mathrm{Er}^{3+}, \mathrm{Yb}^{3+}$ nanopar- ticles (UNPs)}

To a mixture of oleic acid $(11 \mathrm{~mL})$ and octadecene $(10 \mathrm{~mL})$ in a $100 \mathrm{~mL}$ flask, $\mathrm{YCl}_{3} \cdot 6 \mathrm{H}_{2} \mathrm{O}(242.7 \mathrm{mg}$, $0.8 \mathrm{mmol}), \mathrm{YbCl}_{3} \cdot 6 \mathrm{H}_{2} \mathrm{O}(69.7 \mathrm{mg}, 0.18 \mathrm{mmol})$ and $\mathrm{ErCl}_{3} \cdot 6 \mathrm{H}_{2} \mathrm{O}(7.6 \mathrm{mg}, 0.02 \mathrm{mmol})$ were added. The mixture was heated at $100{ }^{\circ} \mathrm{C}$ under vacuum for 1 hour and then cooled to room temperature. Excess solid $\mathrm{NaF}(2.1 \mathrm{~g}, 50 \mathrm{mmol})$ was added and the mixture was then re-heated to $100{ }^{\circ} \mathrm{C}$ under vacuum for 30 minutes. The stirred reaction flask was subsequently put under an $\mathrm{N}_{2}$ atmosphere, the temperature raised rapidly to $320^{\circ} \mathrm{C}$ (at a rate of $\sim 25{ }^{\circ} \mathrm{C} /$ minute), and maintained at this temperature for 1 hour. After cooling to room temperature, the liquid suspension was transferred into two $15 \mathrm{~mL}$ centrifuge tubes, and solid $\mathrm{NaF}$ on the flask bottom was discarded. The liquid suspension was then centrifuged ( 25 minutes, $8900 \mathrm{rpm}$ ) and the supernatant decanted. The resulting pellet was washed 3 times. Each wash step involved re-suspending the pellet in cyclohexane (5 $\mathrm{mL})$, adding ethanol $(20 \mathrm{~mL})$, centrifuging (25 minutes, $8900 \mathrm{rpm}$ ), and removing the supernatant. After the final washing step, the resulting pellet was resuspended in cyclohexane $(\sim 10 \mathrm{~mL})$ and sonicated for $\sim 30$ minutes. Any remaining excess solid $\mathrm{NaF}$ was removed by gravitational sedimentation overnight. Three $100 \mu \mathrm{L}$ aliquots of the UNP suspension were dried in vacuum to determine a UNP concentration of $10 \mathrm{mg} / \mathrm{mL}$.

\section{Synthesis of 58 nm NaYF $4: \mathrm{Er}^{3+}, \mathrm{Yb}^{3+} @ \mathrm{SiO}_{2}$ core/shell nano-composites}

Oleic acid stabilized UNPs in cyclohexane $(0.5$ $\mathrm{mL}$ ) from the previous step were added to cyclohexane $(9.5 \mathrm{~mL})$, before introducing Igepal CO-520 (0.5 $\mathrm{mL}$ ) and $100 \mu \mathrm{L}$ of ammonia solution (27 wt \% in water). The resulting suspension was sonicated for 5 minutes and $20 \mu \mathrm{L}$ of tetraethyl orthosilicate (TEOS) was added. The final suspension was sonicated for 5 minutes and maintained at room temperature for 48 hours on a shaker $(500 \mathrm{rpm})$. The reaction solution was then centrifuged ( 25 minutes, $8900 \mathrm{rpm}$ ) and the supernatant decanted. The resulting pellet was washed by re-suspension in $\sim 12 \mathrm{~mL}$ of ethanol and centrifuged ( 25 minutes, $8900 \mathrm{rpm}$ ) before removing the supernatant. After repeating this washing step 3 times, the resulting pellet $\left(\mathrm{SiO}_{2}\right.$ coated $\mathrm{NaYF}_{4}: \mathrm{Er}^{3+}, \mathrm{Yb}^{3+}, \mathrm{UNP} @ \mathrm{SiO}_{2}$ ) was re-suspended in ethanol. Three $100 \mu \mathrm{L}$ aliquots of the suspension were dried in vacuum to determine a concentration of the $\mathrm{UNP} @ \mathrm{SiO}_{2} \mathrm{NPs}$ of $7 \mathrm{mg} / \mathrm{mL}$.

\section{Synthesis of CyTE-777 triethoxysilane.}

To an ethanol $(4.3 \mathrm{~mL})$ solution containing IR783 (45.0 $\mathrm{mg}, \quad 0.06 \quad \mathrm{mmol})$ and (3-mercaptopropyl)-triethoxysilane (16.7 $\mathrm{mg}, 0.07$ $\mathrm{mmol})$, solid L-arginine $(20.9 \mathrm{mg}, 0.12 \mathrm{mmol})$ was added. The suspension was stirred at $70{ }^{\circ} \mathrm{C}$ for 45 minutes until the reaction was complete, as monitored by mass spectrometry. After cooling, the dark green reaction solution was filtered through a 0.45 micron polytetrafluoroethylene (PTFE) filter to remove the residual solid L-arginine, and was used without any additional purification in the next step. Electrospray ionization mass spectrometry (ESI-MS) negative ion calcd. for $\mathrm{C}_{47} \mathrm{H}_{67} \mathrm{~N}_{2} \mathrm{O}_{9} \mathrm{~S}_{3} \mathrm{Si}^{-}$, 927.38; found, 927.2 (Supplementary Material: Figure S2).

\section{Synthesis of $133 \mathrm{~nm}$ \\ $\mathrm{NaYF}_{4}: \mathrm{Er}^{3+}, \mathrm{Yb}^{3+} @ \mathrm{SiO}_{2} /$ Dye core/shell nano-composites}

To a $5.0 \mathrm{~mL}$ aqueous solution of $200 \mathrm{mM}$ L-arginine in a $20 \mathrm{~mL}$ glass scintillation vial, $715 \mu \mathrm{L}(5$ $\mathrm{mg}$ ) of the ethanolic UNP@SiO 2 stock suspension was added as seed NPs. After sonication of the solution for 5 minutes, the entire CyTE-777 triethoxysilane ethanol solution (prepared in the previous step) was added, to afford $10 \mathrm{~mL}$ of a 1:1 water:ethanol solution containing $100 \mathrm{mM}$ L-arginine. The dark green solution was then sonicated for 30 seconds and placed on a shaker table (300 rpm). After shaking for 60 minutes, TEOS $(130 \mu \mathrm{L}, 0.58 \mathrm{mmol})$ was added and the reaction mixture was allowed to shake at $300 \mathrm{rpm}$ for an additional 4 hours, during which time the solution became slightly cloudy. The reaction solution was then centrifuged (15 minutes, 15,000 G) and the supernatant was decanted. The resulting pellet was washed by resuspension in deionized (DI) water $(5 \mathrm{~mL})$, centrifuged (15 minutes, 15,000 G) and the supernatant was removed. After repeating the washing step 3 times, the pellet (UNP@SiO $/$ Dye) was resuspended in DI water. Five identical reactions were performed in parallel. After washing, all reactions were combined and resuspended in $4.7 \mathrm{~mL}$ of DI water. Three $150 \mu \mathrm{L}$ aliquots of the reaction were dried in vacuum to determine a final concentration of the UNP@SiO $2 /$ Dye core/shell nano-composites of $41 \mathrm{mg} / \mathrm{mL}$.

\section{Nanomaterial characterization}

Sizes and morphologies of the NPs were determined at $200 \mathrm{kV}$ using a JEOL JEM-2100 
high-resolution transmission electron microscope (HR-TEM). Samples of the as-prepared NPs were prepared by placing a drop of dilute aqueous dispersion on the surface of a copper grid. The size distribution of NPs in aqueous solution was measured by dynamic light scattering (DLS) carried out on a Malvern Zetasizer Nano ZS with a He-Ne laser (633 nm). The samples of NPs were prepared in aqueous solution at a concentration of $\sim 0.1 \mathrm{mg} / \mathrm{mL}$. All measurements were carried out at $25{ }^{\circ} \mathrm{C}$ and data were analyzed by the Malvern software. Up-conversion luminescence spectra of the NPs were measured with a Horiba Jobin-Yvon Fluorolog-3 fluorescence spectrometer modified with an external $980-\mathrm{nm}$ CW fiber-coupled laser operating at $300 \mathrm{~mW}$ (output) as the excitation source. Ultra-violet/visible (UV-vis) spectra were recorded on a Cary UV/vis spectrophotometer. Fluorescence measurements were obtained using a Varian Cary Eclipse fluorescence spectrophotometer.

\section{Up-conversion cell imaging}

Macrophage RAW cells were divided into each well of an 8-well chamber slide before being treated with the nano-composites (final concentration $~ 100$ $\mu \mathrm{g} / \mathrm{mL}$ ) at $37{ }^{\circ} \mathrm{C}$ for 2 hours. The cells were then washed twice with Dulbecco's Phosphate-Buffered Saline (DPBS; pH 7.4, 1 mM). Fixation buffer (BD Cytofix ${ }^{\mathrm{TM}}$ ) was added to fix the cells for 20 minutes and the cells were then washed twice with DPBS ( $\mathrm{pH} 7.4,1$ $\mathrm{mM})$. ProLong ${ }^{\circledR}$ Gold antifade reagent with DAPI was used for cell staining. Cell imaging was performed on an Olympus IX71 microscope with an $875 \mathrm{~nm}$ short pass dichroic mirror and an UPlanApo 60x NA 1.2 water immersion lens. NIR imaging was carried out using a CW 980-nm laser source operating at $300 \mathrm{~mW}$ (output). DAPI imaging was performed using a CW 405-nm laser and appropriate filters.

\section{Photo-thermal testing}

Leukemic monocyte/macrophage (RAW 264.7) cells were used for testing. All cells were maintained in a $5 \% \mathrm{CO}_{2}$, water-saturated atmosphere and grown in DMEM media supplemented with $10 \%$ fetal bovine serum (FBS), 1\% penicillin streptomycin, 1\% L-glutamine and $2 \% \mathrm{Na}_{2} \mathrm{CO}_{3}$. RAW cells were seeded in a 96-well plate at a density of $\sim 17,500$ cells per well and were allowed to grow overnight before incubating with the nano-composites. The cells were incubated at $37{ }^{\circ} \mathrm{C}$ for 3 hours with the NPs at a final concentration of $1 \mathrm{mg} / \mathrm{mL}$. After removing the nanomaterial-containing cell media, $100 \mu \mathrm{L}$ of DPBS buffer was added to each well. The cells were then subjected to photo-thermal testing. In the testing, a CW 750-nm diode laser operating at $1 \mathrm{~W} / \mathrm{cm}^{2}$ was used to illu- minate the cells for 3 minutes. Cell viability was assessed with the MTS ((3-(4,5-dimethylthiazol2-yl)-5-(3-carboxymethoxyphenyl)-2-(4- sulfophenyl)$2 \mathrm{H}$-tetrazolium)) assay. The assay solution was prepared by diluting the CellTiter 96 AQueousone solution reagent (Promega) 6-fold with cell media. After removing the DPBS buffer, $120 \mu \mathrm{L}$ of the assay solution was added to each well and the plate was incubated for 1 hour at $37{ }^{\circ} \mathrm{C}$ in a humidified, $5 \% \mathrm{CO}_{2}$ atmosphere. The absorbance of each well at $490 \mathrm{~nm}$ was then recorded by an XFluor4 96-well plate reader (TECAN) to determine cell viability. A reference wavelength of $665 \mathrm{~nm}$ was used to subtract the background.

\section{Results and Discussion}

The $\mathrm{NaYF}_{4}: \mathrm{Er}^{3+}, \mathrm{Yb}^{3+} \mathrm{NPs}$ were synthesized in solution via a thermal precipitation process (Figure $1 \mathrm{~A})$. The as-synthesized UNPs, which have an average diameter of $40 \mathrm{~nm}$ (Figure 1B) are hydrophobic due to the coordination of oleic acid on the surface of the UNPs. Although not entirely pure, the upconverting core largely consists of hexagonal-phase $\mathrm{NaYF}_{4}$ with no observed cubic-phase material (Supplementary Material: Figure S6). During the course of this work, we found that the oleic acid stabilized UNPs tend to aggregate on prolonged standing and can be difficult to re-disperse. Therefore, the core UNPs were converted to a more stable preparation by growing a thin silica $\left(\mathrm{SiO}_{2}\right)$ shell on the UNP surface. This was accomplished via an inverse micro-emulsion procedure. The resulting $\mathrm{UNP} @ \mathrm{SiO}_{2}$ have an average diameter of $58 \mathrm{~nm}$ (Figure 1C), are readily dispersible in water or ethanol, and do not aggregate in water even after storage for more than one year. The $\mathrm{UNP} @ \mathrm{SiO}_{2}$ were thus used as a starting point for preparing the final composite NPs by growing a second silica shell in the presence of CyTE-777 triethoxysilane (Supplementary Material: Figure S1). CyTE-777 triethoxysilane is a silane-modified NIR dye that becomes covalently cross-linked into the outer silica shell. It can be readily prepared via modification of a previously reported procedure, which involves nucleophilic attack of the thiolate group of (3-mercaptopropyl)-triethoxysilane on the commercially available IR783 dye [40]. The final composite $\mathrm{UNP} @ \mathrm{SiO}_{2} /$ Dye NPs have an average diameter of 133 $\mathrm{nm}$ (Figure 1D). The overall synthetic scheme and TEM images for each stage of the synthesis are shown in Figure 1, and Table 1 summarizes the size of the NP preparations as determined by TEM and light scattering measurements. Furthermore, the $\mathrm{UNP} @ \mathrm{SiO}_{2} /$ Dye nano-composites show good long-term stability in water (Supplementary Material: Figure S5). Based on the TEM size measurements, the 
outer $\mathrm{SiO}_{2}$ shell, which contains the cross-linked NIR absorbing CyTE-777, accounts for $83 \%$ of the total NP volume, whereas the UNP core is only $3 \%$ of the total volume.This indicates that the majority of the nano-composite volume comes from the layer that contains the NIR dye used for the photo-thermal heating.

The UNP@SiO 2 /Dye nano-composites show strong optical absorbance in the NIR with peaks at 712 and $785 \mathrm{~nm}$ (Figure 2A) originating from the doped CyTE-777 silane dye. The extinction coefficients of the composite particles are $2.53 \pm 0.04 \times 10^{9} \mathrm{M}^{-1} \mathrm{~cm}^{-1}$ and $1.89 \pm 0.04 \times 10^{9} \mathrm{M}^{-1} \mathrm{~cm}^{-1}$ at the $785 \mathrm{~nm}$ absorption maximum, and at $750 \mathrm{~nm}$, which is used for photo-thermal excitation, respectively (Supplementary Material: Figure S4). The prominent short wavelength peak in the composite at $712 \mathrm{~nm}$ is indicative of strong dye aggregation [41] and the fluorescence emission from the organic dyes in the composite is quenched (Supplementary Material: Figure S3). Aggregation of the dye molecules within the silica shell can be seen clearly when the absorption spectra of the composite particles and free IR873 are compared (Supplemen- tary Material: Figure S3). This is in good agreement with previous reports which indicated that the inclusion of organic dyes into NPs can quench dye fluorescence and concentrate the dye molecules for improved localized heating [42]. In contrast to the quenched fluorescence from the organic dye in the $\mathrm{UNP} @ \mathrm{SiO}_{2}$ /Dye composite, the UNP core particles still show good upconversion emission. Upon $980 \mathrm{~nm}$ excitation of the nano-composite, strong emission at $545 \mathrm{~nm}$ and weaker emission in the far-red centered at $660 \mathrm{~nm}$ is observed (Figure 2B).

Table I. Size comparison of the different nanoparticles by transmission electron microscopy (TEM) and dynamic light scattering (DLS).

\begin{tabular}{lll}
\hline NPs & Size by TEM $(\mathrm{nm})$ & $\begin{array}{l}\text { Size (PDI) by DLS } \\
(\mathrm{nm})\end{array}$ \\
\hline $\mathrm{UNP}$ & $40 \pm 1.5$ & $42(0.109)$ in hexane \\
$\mathrm{UNP@SiO} 2$ & $58 \pm 2$ & $79(0.043)$ in water \\
$\mathrm{UNP@SiO} / 2$ Dye & $133 \pm 2$ & $179(0.027)$ in water \\
\hline
\end{tabular}
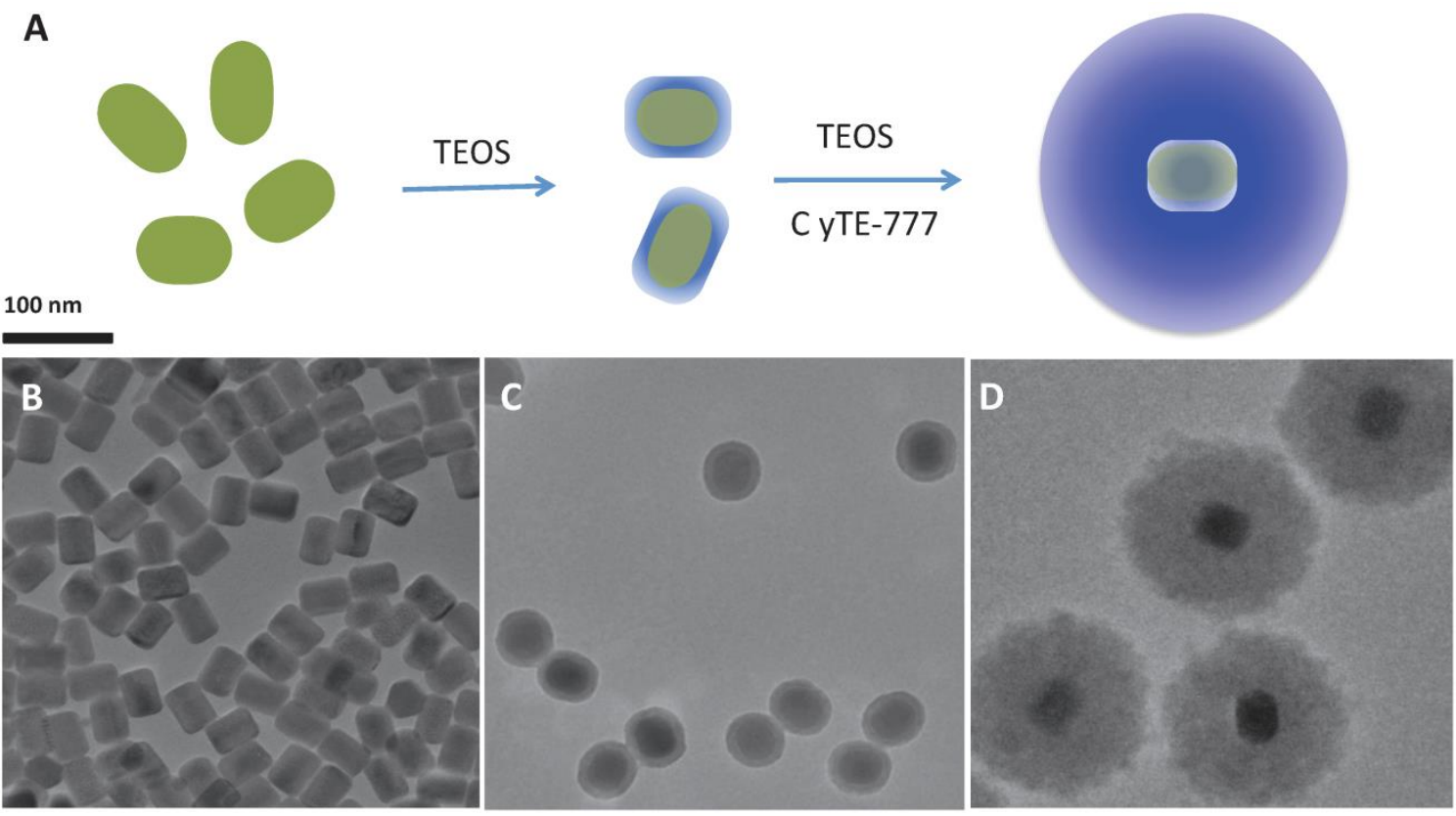

Figure 1. (A): Synthetic scheme and (B-D): TEM images (B, upconverting nanoparticles (UNPs); C, UNP@SiO2 core/shell nanoparticles; $\mathrm{D}, \mathrm{UNP} @ \mathrm{SiO}_{2} /$ Dye nano-composites) of the nanoparticles. 

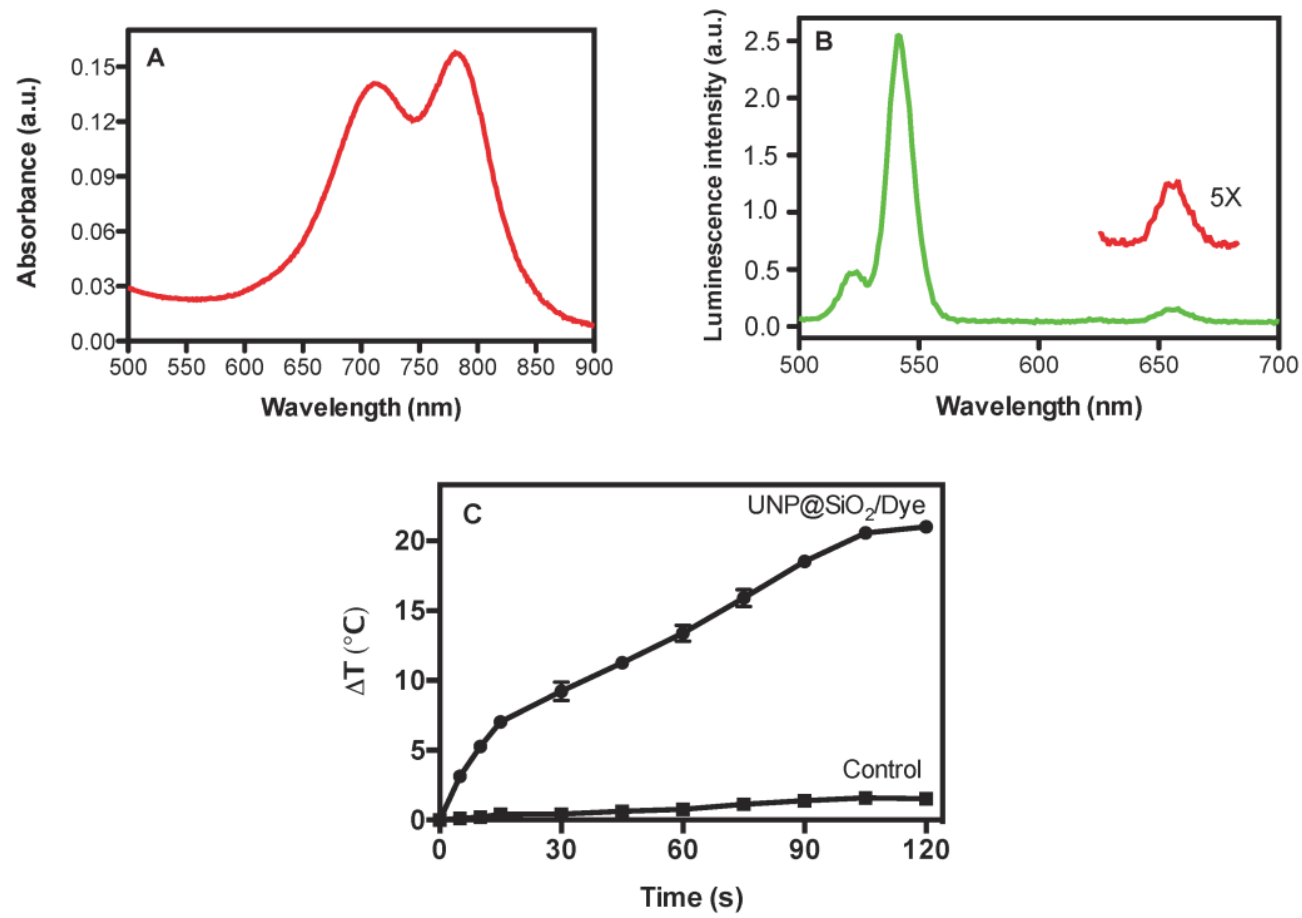

Figure 2. Optical and heating properties of UNP@SiO $/$ Dye nano-composites. (A): Absorbance spectrum of UNP@SiO $2 / \mathrm{Dye}$; $(\mathrm{B})$ : Up-conversion luminescence spectrum of UNP@SiO2/Dye; (C): Temperature change (Delta temperature) of a $2.0 \mathrm{mg} / \mathrm{mL}$ aqueous suspension of UNP@SiO $/$ Dye and control solution upon irradiation with a $750-\mathrm{nm}$ laser $\left(2.5 \mathrm{~W} / \mathrm{cm}^{2}\right)$.

The UNP@SiO $/$ Dye nano-composite demonstrates good photo-thermal heating properties in aqueous suspension. The temperature changes for an aqueous suspension of the nano-composite $(2.0$ $\mathrm{mg} / \mathrm{mL}$ ) and for a water-only control under irradiation with a 750-nm laser over time, are shown in Figure 2C. After 120 seconds of irradiation, the temperature in the nano-composite suspension increased to $21^{\circ} \mathrm{C}$. Since it is well known that gold nanorods are one of the most effective materials for photothermal heating $[1,3]$, we chose to assess the performance of the UNP@SiO 2 /Dye nano-composites by comparing them directly with a commercially available gold nanorod preparation. Under identical conditions to those used for the UNP@SiO $2 /$ Dye nano-composite heating experiment, a temperature increase of $27{ }^{\circ} \mathrm{C}$ was obtained for the gold nanorods (Supplementary Material: Fig. S7). With our specific experimental setup, according to the Beer-Lambert Law, heating efficiencies for the UNP@SiO $/$ Dye nano-composite and gold nanorods, were approximately $14 \%$ and $16 \%$, respectively (See details in Supplementary Materials). While less efficient than gold nanorods, the $\mathrm{UNP} @ \mathrm{SiO}_{2}$ /Dye nano-composites may still offer sufficient performance as to be useful as a PTT agent.

Macrophage RAW cells were used as a proof-of-principle model system for testing cell imaging and the PTT performance of the nano-composite. Images of the cells after incubation with the UNP@SiO 2 /Dye nano-composite are shown in Figure 3. These experiments demonstrate that the RAW cells are effective in taking up the nano-composite and can be easily visualized via upconversion imaging using a $980 \mathrm{~nm}$ excitation source. The photo-thermal properties of the nano-composite were examined by subjecting nano-composite-incubated cells to treatment with a $750 \mathrm{~nm}$ CW diode laser, operating at $1 \mathrm{~W} / \mathrm{cm}^{2}$ for 3 minutes. These experiments (Figure 4) indicate that $42 \%$ of the RAW cells are killed when using the nano-composite under the $750 \mathrm{~nm}$ laser excitation. In contrast, the cell loss observed under the same conditions using a $980 \mathrm{~nm}$ laser $\left(1 \mathrm{~W} / \mathrm{cm}^{2}\right)$ was statistically insignificant. Similar cell killing efficiencies were recently reported using related nano-composites and employing a UNP core with singlet oxygen generating dyes for photodynamic therapy [43]. Ultimately, the data from our experiments demonstrate that the diagnostic and PTT functions triggered by $980 \mathrm{~nm}$ and $750 \mathrm{~nm}$ excitation, respectively, are discrete within the nano-composite, and do not interfere with one another.

These dual-function nano-composites therefore have advantages over previously reported systems that use organic dyes for both fluorescence imaging and PTT $[38,44]$, since the latter could result in unintended photo-thermal heating during optical imaging. 


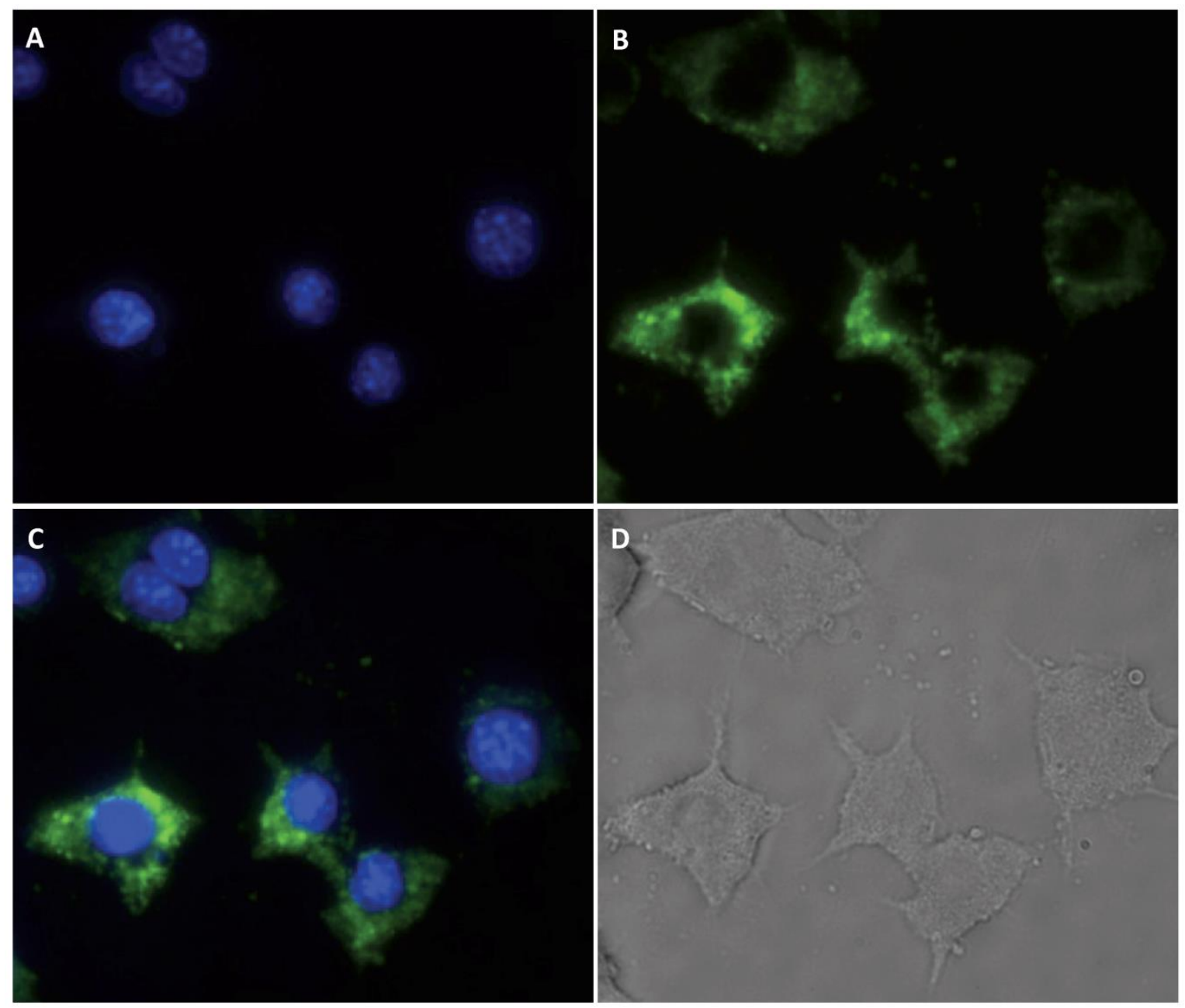

Figure 3. Cell images of macrophages (RAW). (A): DAPI nuclear stain; (B) Upconversion emission; (C): Composite of $A$ and B; and (D): White light.

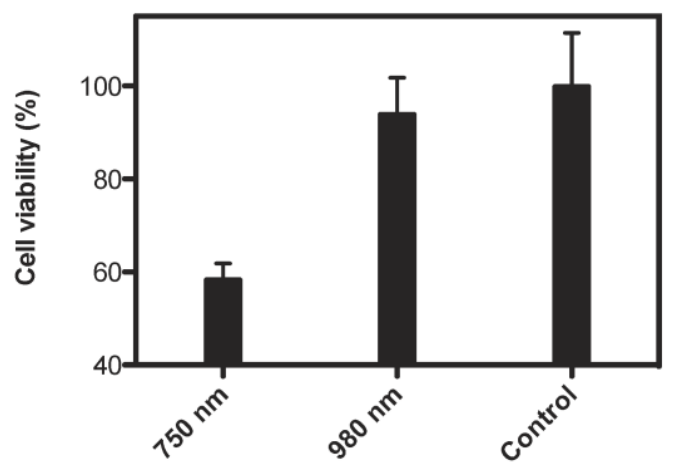

Figure 4. Cell viability of macrophages (RAW) using UNP@SiO $/$ Dye nano-composites(Irradiation time: 3 minutes; I W/cm² at 750 or $980 \mathrm{~nm}$ ) Control cells were incubated with the nano-composite but not subjected to light treatment.

\section{Conclusion}

New $\quad \mathrm{NaYF}_{4}: \mathrm{Er}^{3+}, \mathrm{Yb}^{3+} @ \mathrm{SiO}_{2} /$ Dye core-shell nano-composites were designed and synthesized for combined NIR imaging and photo-thermal therapy.
Cells incubated with the nano-composites can be visualized clearly by upconversion imaging using 980 $\mathrm{nm}$ excitation. In addition, photo-thermal cell killing with the nano-composite is demonstrated via exclusive excitation of the NIR dyes doped within the silica 
shell of the nano-composite using a $750 \mathrm{~nm}$ light source. This work is a proof-of-principle demonstration that diagnostic optical imaging and therapeutic thermal therapy methodologies can be combined in a single nanomaterial. By further modifying the silica surface of this new NP platform to incorporate targeting ligands, in vivo targeting, diagnosis, and therapy may be possible.

\section{Supplementary Materials}

Figures S1-S7 detail additional characterization of the organic dye and nano-composite. http://www.thno.org/v03p0267s1.pdf

\section{Acknowledgment}

This research is supported in part by NHLBI contract HHSN268201000044C.

\section{Competing Interests}

The authors have declared that no competing interest exists.

\section{References}

1. El-Sayed IH, Huang X, El-Sayed MA. Selective laser photo-thermal therapy of epithelial carcinoma using anti-EGFR antibody conjugated gold nanoparticles. Cancer Lett. 2006; 239(1): 129-135.

2. Philipp CM, Rohde E, Berlien HP. Nd:YAG laser procedures in tumor treatment. Semin Surg Oncol. 1995; 11: 290-298.

3. Dolmans DEJGJ, Fukumura D, Jain RK. Photodynamic therapy for cancer. Nat Rev Cancer. 2003: 3: 380e7.

4. Link S, El-Sayed MA. Spectral Properties and Relaxation Dynamics of Surface Plasmon Electronic Oscillations in Gold and Silver Nanodots and Nanorods. J Phys Chem B. 1999; 103 (40): 8410-8426.

5. Park J-H, von Maltzahn G, Ong LL, Centrone A, Hatton TA, Ruoslahti E, et al. Cooperative Nanoparticles for Tumor Detection and Photothermally Triggered Drug Delivery. Adv Mater. 2010; 22: 880-885.

6. Kam NWS, O'Connell M, Wisdom JA, Dai H. Carbon nanotubes as multifunctional biological transporters and near-infrared agents for selective cancer cell destruction. Proc Natl Acad Sci USA. 2005; 102: 11600-11605.

7. Chakravarty P, Marches R, Zimmerman NS, Swafford AD-E, Bajaj P, Musselman IH, et al. Thermal ablation of tumor cells with antibody-functionalized single-walled carbon nanotubes. Proc Natl Acad Sci USA. 2008;105: 8697-8702.

8. Ghosh S, Dutta S, Gomes E, Carroll D, D'Agostino JrR, Olson J, et al. Increased Heating Efficiency and Selective Thermal Ablation of Malignant Tissue with DNA-Encased Multiwalled Carbon Nanotubes. ACS Nano. 2009; 3: 2667-2673.

9. Moon HK, Lee SH, Choi HC. In Vivo Near-Infrared Mediated Tumor Destruction by Photothermal Effect of Carbon Nanotubes. ACS Nano. 2009; 3: 3707-3713.

10. Rossella F, Soldano C, Bellani V, Tommasini M. Metal-Filled Carbon Nanotubes as a Novel Class of Photothermal Nanomaterials. Adv Mater. 2012; 24(18): 2453-2458.

11. Chu M, Pan X, Zhang D, Wu Q, Peng J, Hai W. The therapeutic efficacy of $\mathrm{CdTe}$ and CdSe quantum dots for photothermal cancer therapy. Biomater. 2012; 33(29): 7071-7083

12. Akhavan O, Ghaderi E, Aghayee S, Fereydooni Y, Talebi A. The use of a glucose-reduced graphene oxide suspension for photothermal cancer therapy. Mater Chem. 2012; 22:13773-13781.

13. Nie SM, Xing Y, Kim GJ, Simons JW. Nanotechnology applications in cancer. Annu Rev Biomed Eng. 2007; 9: 257-288.

14. Weissleder R. A clearer vision for in vivo imaging. Nat Biotechnol. 2001;19: 316-317.

15. O'Neal DP, Hirsch LR, Halas NJ, Paynea JD, West JL. Photo-thermal tumor ablation in mice using near infrared-absorbing nanoparticles. Cancer Lett. 2004; 209: 171-176.

16. Giljohann DA, Seferos DS, Daniel WL, Massich MD, Patel PC, Mirkin CA. Gold Nanoparticles for Biology and Medicine. Angew Chem Int Ed. 2010, 49: 3280-3294.
17. Jain PK, Huang X, El-Sayed IH, El-Sayed MA. Noble metals on the nanoscale: optical and photothermal properties and applications in imaging, sensing, biology, and medicine. Acc Chem Res. 2007; 41: 1578e86.

18. Alkilany AM, Thompson LB, Boulos SP, Sisco PN, Murphy CJ. Gold nanorods: their potential for photothermal therapeutics and drug delivery, tempered by the complexity of their biological interactions. Adv Drug Deliv Rev. 2012; 64(2): 190-199.

19. Kennedy LC, Bickford LR, Lewinski NA, Coughlin AJ, Hu Y, Day ES, et al. A New Era for Cancer Treatment: Gold-Nanoparticle- Mediated Thermal Therapies. Small. 2011; 7(2): 169-183.

20. von Maltzahn G,Park J-H, Agrawal A, Bandaru NK, Das SK,Sailor MJ, Bhatia SN. Computationally Guided Photothermal Tumor Therapy Using Long-Circulating Gold Nanorod Antennas. Cancer Res. 2009; 69(9): 3892-3900.

21. Loo C, Lowery A, Halas N, West J, Drezek R. Immunotargeted nanoshells for integrated cancer imaging and therapy. Nano Lett. 2005; 5(4): 709-711.

22. Skrabalak SE, Au L, Lu XM, Li XD, Xia YN. Gold nanocages for cancer detection and treatment. Nanomedicine. 2007; 2: 657-668.

23. Zhang JZ. Biomedical Applications of Shape-Controlled Plasmonic Nanostructures: A Case Study of Hollow Gold Nanospheres for Photothermal Ablation Therapy of Cancer. J Phys Chem Lett. 2010; 1: 686- 695.

24. Rosi NL, Mirkin CA. Nanostructures in Biodiagnostics. Chem Rev. 2005, 105: 1547-1562.

25. Alkilany AM, Thompson LB, Boulos SP, Sisco PN, Murphy CJ. Gold nanorods: Their potential for photothermal therapeutics and drug delivery, tempered by the complexity of their biological interactions. Adv Drug Delivery Rev. 2012; 64: 190-199.

26. Choi WI, Sahu A, Kim YH, Tae G. Photothermal cancer therapy and imaging based on gold nanorods. Ann Biomed Eng. 2012; 40(2): 534-546.

27. Huang X, El-Sayed IH, Qian W, El-Sayed MA. Cancer cell imaging and photothermal therapy in the near-infrared region by using gold nanorods. J Am Chem Soc. 2006;128(6): 2115-2120.

28. El-Sayed IH, Huang X, El-Sayed MA. Selective laser photo-thermal therapy of epithelial carcinoma using anti-EGFR antibody conjugated gold nanoparticles. Cancer Lett. 2006; 239(1): 129-135.

29. Choi R, Yang J, Choi J, Lim EK, Kim E, Suh JS, et al. Thiolated Dextran-Coated Gold Nanorods for Photothermal Ablation of Inflammatory Macrophages. Langmuir. 2010; 26(22): 17520-17527.

30. Khan SA, Kanchanapally R, Fan Z, Beqa L, Singh AK, Senapati D, et al. A gold nanocage-CNT hybrid for targeted imaging and photothermal destruction of cancer cells. Chem Commun. 2012; 48: 6711-6713.

31. Yang P, Xu QZ, Jin SY, Lu Y, Zhao Y, Yu SH. Synthesis of multifunctional Ag@Au@Phenol formaldehyde resin particles loaded with folic acids for photothermal therapy. Chemistry - A Euro J. 2012; 18(30): 9294-9299.

32. Weissleder R, Ntziachristos V. Shedding light onto live molecular targets. Nat Med. 2003; 9: 123-128.

33. Dolmans DEJGJ, Fukumura D, Jain RK. Photodynamic therapy for cancer. Nat Rev Cancer. 2003; 3: 380-387.

34. Jarvi MT, Niedre MJ, Patterson MS, Wilson BC. Singlet oxygen luminescence dosimetry (SOLD) for photodynamic therapy: current status, challenges and future prospects. Photochem Photobiol. 2006; 82: 1198e210.

35. Chen WR, Adams RL, Bartels KE, Nordquist RE. Chromophore-enhanced in vivo tumor- cell destruction using an 808-Nm diode-laser. Cancer Lett. 1995; 94: $125-131$

36. Chen WR, Adams RL, Higgins AK, Bartels KE, Nordquist RE. Photothermal effects on murine mammary tumors using indocyanine green and an 808-nm diode laser: an in vivo efficacy study. Cancer Lett. 1996; 98: 169-173.

37. Resch-Genger U, Grabolle M, Cavaliere-Jaricot S, Nitschke R, Nann T. Quantum dots versus organic dyes as fluorescent labels. Nat Method. 2008; 5: 763-775.

38. Gutwein LG, Singh AK, Hahn MA, Rule MC, Knapik JA, Moudgil BM, et al. Fractionated photothermal antitumor therapy with multidye nanoparticles. Inter J Nanomedicine. 2012; 7: 351-357.

39. Haase M, Schäfer H. Upconverting Nanoparticles. Angew Chem Int Ed. 2011; 50: 5808-5829.

40. Hilderbrand SA, Kelly KA, Weissleder $\mathrm{R}$, Tung $\mathrm{CH}$. Monofunctional near-infrared fluorochromes for imaging applications. Bioconjug Chem. 2005;16(5):1275-1281

41. Galande AK, Hilderbrand SA, Weissleder R, Tung CH. Enzyme-targeted fluorescent imaging probes on a multiple antigenic peptide core. J Med Chem. 2006; 49(15):4715-4720

42. Saxena V, Sadoqi M, Shao J. Enhanced photo-stability, thermal-stability and aqueous stability of indocyanine green in polymeric nanoparticulate systems. J Photochem Photobiol B Biol. 2004; 74: 29e38.

43. Idris NM, Gnanasammandhan MK, Zhang J, Ho PC, Mahendran R, Zhang Y. In vivo photodynamic therapy using upconversion nanoparticles as remote-controlled nanotransducers. Nature Medicine 2012; 18: 1580-1585.

44. Singh AK, Hahn MA, Gutwein LG, Rule MC, Knapik JA, Moudgil BM, Grobmyer SR, Brown SC. Multi-dye theranostic nanoparticle platform for bioimaging and cancer therapy. Int J Nanomedicine. 2012;7:2739-2750. 